\title{
Effect of electron irradiation on excess conductivity of single $\mathrm{Y}_{1} \mathrm{Ba}_{2} \mathrm{Cu}_{3} \mathrm{O}_{7-\delta}$ crystals
}

\author{
N.A.Azarenkov ${ }^{1}$, V.N.Voevodin ${ }^{1,2}$, R.V.Vovk ${ }^{1}$, \\ S.R.Vovk ${ }^{1}$, G.Ya.Khadzhai ${ }^{1}$, V.V.Sklyar ${ }^{1}$ \\ ${ }^{1}$ V.Karazin Kharkiv National University, 4 Svobody Sq., 61022 Kharkiv, \\ Ukraine \\ ${ }^{2}$ Institute of Solid State Physics, Materials Science and Technologies, \\ NSC-KIPT, 1 Akademichna St., 61108 Kharkiv, Ukraine
}

\author{
Received December 3, 2017
}

Effect of electron irradiation on the excess conductivity of $\mathrm{YBa}_{2} \mathrm{Cu}_{3} \mathrm{O}_{7-\delta}$ single crystals is investigated. It is shown that irradiation with electrons leads to significant expansion of the temperature interval that excess conductivity exists. The excess conductivity $\Delta \sigma(T)$ has been revealed to obey an exponential temperature dependence in the broad temperature range $T_{f}<T<T^{*}$. The description of the excess conductivity can be interpreted in terms of the mean-field theory where $T^{*}$ is the mean-field transition temperature to the pseudogap state and $\Delta^{*}(T)$ is satisfactory described within the framework of the BCS-BEC crossover theory. The value of the transverse coherence length $\xi_{c}(0)$ increases by a factor of 1.4 and the point of 2D-3D crossover shifts with respect to temperature.

Keywords: excess conductivity, electron irradiation, YBaCuO single crystals, crossover.

Исследована эволюция избыточной проводимости монокристаллов $\mathrm{YBa}_{2} \mathrm{Cu}_{3} \mathrm{O}_{7-\delta}$ при облучении электронами. Показано, что облучение электронами приводит к значительному расширению температурного интервала существования избыточной проводимости, тем самым сужая область линейной зависимости $\rho(T)$ в $a b$-плоскости. Установлено, что избыточная проводимость $\Delta \sigma(T)$ монокристаллов $\mathrm{YBa}_{2} \mathrm{Cu}_{3} \mathrm{O}_{7-\delta}$ в широком интервале температур $T_{f}<T<T^{*}$ подчиняется экспоненциальной температурной зависимости. Описание избыточной проводимости может быть интерпретировано в терминах теории среднего поля, где $T^{*}$ представлена, как среднеполевая температура перехода в Пщ-состояние, а температурная зависимость псевдощели удовлетворительно описывается в рамках теории кроссовера БКШ-БЭК. Величина поперечной длины когерентности $\xi_{c}(0)$ увеличивается в 1,4 раза и смещается по температуре точка 2D-3D кроссовера.

Вплив опромінення електронами на надлишкову провідність монокристалів $\mathrm{Y}_{1} \mathrm{Ba}_{2} \mathrm{Cu}_{3} \mathrm{O}_{7-\delta}$. М.ОАзаренков, В.М.Воєводін, Р.В.Вовк, С.Р.Вовк, Г.Я.Хаджай, В.В.Скляр.

Досліджено еволюцію надлишкової провідності монокристалів $\mathrm{YBa}_{2} \mathrm{Cu}_{3} \mathrm{O}_{7-\delta}$ при опроміненні електронами. Показано, що опромінення електронами приводить до значного розширення температурного інтервалу існування надлишкової провідності, тим самим, звужуючи область лінійної залежності $\rho(T)$ в $a b$-площині. Встановлено, що надлишкова провідність $\Delta \sigma(T)$ монокристалів $\mathrm{YBa}_{2} \mathrm{Cu}_{3} \mathrm{O}_{7-\delta}$ в широкому інтервалі температур $T_{f}<T<$ $T^{*}$ підкоряється експоненціальній температурній залежності. Описання надлишкової провідності може бути інтерпретовано у термінах теорії середнього поля, де $T^{*}$ представлена, як середньопольова температура переходу у ПЩ-стан, а температурна залежність псевдощілини задовільно описується у рамках теорії кросовера БКШ-БЕК. Величина поперечної довжини когерентності $\xi_{c}(0)$ збільшується в 1,4 рази і зміщується за температурою точка 2D-3D кросовера. 


\section{Introduction}

The question of effect of dimensionality on the superconducting state formation in high-temperature superconducting cuprates (HTSC) remains open, despite the intense experimental and theoretical studies carried out in the last 30 years [1-3]. As it is established $[1,4]$, the large penetration depth, the short coherence length and the layered structure contribute to appearance of an anomalously wide region of excess conductivity $(\Delta \sigma)$ in HTSC compounds in $\rho_{a b}(T)$ dependences (in the basal plane). Far from the critical temperature $\left(T_{c}\right)$ at $T_{c} \leq T$ $<T^{*}$ (where $T^{*}$ is the temperature that deviation from the linear in the $\rho_{a b}(T)$ dependence commences), $\Delta \sigma$ is determined by the so-called pseudogap anomaly (PG) [5-7], which was previously studied in detail in [8]. Near $T_{c}, \Delta \sigma$ is caused due to formation of fluctuation superconducting pairs $[9,10]$. Therewith, the width and character of the behavior of fluctuation para-conductivity (FC) section essentially depends on the composition and structure of an experimental sample [1, $11,12]$, such as on the presence or absence of the extreme external influences [13, 14].

At the present time, it can be reliably considered that near $T_{c}$ the $\Delta \sigma(T)$ dependence is always well described within the framework of the Aslamazov-Larkin theory [9] for three-dimensional paraconductivity. During the transition through 2D-3D crossover point, these curves can be well described in the framework of the LorentzDoniach model [15] or the Maki-Thompson process [16], depending on the degree of perfection of each particular experimental sample [17]. High pressure [13, 18], hightemperature annealing [19], along with the long-term aging processes [20], can substantially shift the 3D crossover point, and also lead to the phase separation [14] as a result of the structural relaxation induced by these extreme conditions. The magnetic field, as a rule, leads to a significant blurring of the superconducting transition [21,22] due to appearance of specific dynamic transitions in the SC subsystem. Exceptions are the cases of strong pinning of the SC fluctuations on modulated defect superstructure in the form of developed twinning grid [23], etc.

Notably, despite the large number of works, new studies of the influence of external impacts on the fluctuation conductivity in HTSC, there is practically no regarding the effect of irradiation on the FC. The latter, can significantly change both the ab- solute value of the electrical resistivity $\rho$ and the nature of its temperature dependences $\rho(T)$ [24]. This apart from its fundamental aspect, has a great practical importance, given the very large number of various instruments and devices developed and produced in recent years on the basis of HTSC materials for operation in conditions with the high radiation activity.

In the present study, the effect of electron irradiation on the phase transition and the 2D-3D crossover in superconductor was studied. Choice of the latter as an object of investigation was due to its high critical temperature $T_{c} \approx 90 \mathrm{~K}[25]$ exceeding the boiling point of liquid nitrogen and the greater possibilities for varying its conductive characteristics by doping with substitute elements $[26,27]$ or by varying the degree of deviation from oxygen stoichiometry [28,29].

\section{Experimental}

The $\mathrm{YBa}_{2} \mathrm{Cu}_{3} \mathrm{O}_{7-\delta}$ single crystals were grown by solution-melt procedure in a gold crucible [29]. The technology of obtaining experimental samples and conducting resistive measurements, as well as the analysis of the transport properties of the samples in the normal and superconducting states, are described in detail in $[27,29]$. Irradiation with electrons with energies 0.5 to $2.5 \mathrm{MeV}$ was carried out at temperatures $T<10 \mathrm{~K}$. Irradiation densities of $\varphi=10^{18} 1 / \mathrm{cm}^{2}$ by electrons with energy of $2.5 \mathrm{MeV}$ correspond to the average concentration of defects at all sublattices of $10^{-4} \mathrm{dpa} /$ at. displacements per atom [30]. The sequence of measurements was as follows: first, the temperature dependences of the samples resistivity of before irradiation were measured. Then the temperature was lowered to $5 \mathrm{~K}$ and the samples were irradiated. The intensity of the beam was such that the temperature of the sample did not exceed $10 \mathrm{~K}$ during the irradiation process. After irradiating the sample was heated to $300 \mathrm{~K}$ and, gradually decreasing the temperature (of the sample), measurements of the temperature dependences of the resistivity at $T<300 \mathrm{~K}$ were carried out. The resistivity parameters of the samples are shown in the Table.

\section{Results and discussion}

The temperature dependences of the resistivity in ab-plane $\rho_{a b}(T)$ of the $\mathrm{YBa}_{2} \mathrm{Cu}_{3} \mathrm{O}_{7-\delta}$ single crystal before and after irradiation are shown in Fig. 1. As it can be seen from Fig. 1, the irradiation leads to an anomalously strong 
Table. Resistivity parameters of experimental sample.

\begin{tabular}{|c|c|c|c|c|c|c|c|c|c|c||}
\hline Sample & $T_{c}, \mathrm{~K}$ & $\begin{array}{c}\rho_{a b}(300), \\
\mu \Omega \cdot \mathrm{cm}\end{array}$ & $T^{*}, \mathrm{~K}$ & $\begin{array}{c}\Delta^{*}{ }_{a b}, \\
\mathrm{meV}\end{array}$ & $T_{f}, \mathrm{~K}$ & $\begin{array}{c}t^{*}{ }^{*} \\
\left(T^{*}-T_{f}\right) / T_{f}\end{array}$ & $\alpha_{1}$ & $\alpha_{2}$ & $\varepsilon_{0}$ & $\xi_{c}(0), \AA$ \\
\hline $\begin{array}{c}\text { Before } \\
\text { irradiation } \\
\begin{array}{c}\text { After } \\
\text { irradiation }\end{array}\end{array}$ & 91.7 & 199 & 137 & 97.1 & 95.5 & 0.3029 & -0.5039 & -1.0163 & 0.0603 & 1.44 \\
\hline \hline
\end{tabular}

suppression of the superconductivity in the $\mathrm{YBa}_{2} \mathrm{Cu}_{3} \mathrm{O}_{7-\delta}$ crystal (in comparison with the change in its composition [31]).

Nevertheless, the nature of changes in the electrical and superconducting properties of the HTSCs by varying composition [31] and under irradiation is different. The main difference is as follows: while changing the composition, decrease in $T_{c}$ to $86 \mathrm{~K}$ is usually accompanied by a change in the shape of $\rho(T)$ curves from the metallic curve to the so-called "S-shaped curve" with characteristic thermal activation deflection [31], in the irradiation, the same absolute decrease in $T_{c}$ with appreciable increase of $\rho$ in the temperature interval $T_{c}-300 \mathrm{~K}$ is not accompanied by appearance of the S-shaped $\rho(T)$ dependence. The thermo-activation behavior of the electrical resistance in the irradiated samples is manifested only at sufficiently low values of $T_{c}$ [32]. One of the reasons that lead to the significant decrease in $T_{c}$ of the irradiated samples could be appearance of dielectric inclusions under the influence of irradiation, due to the redistribution of oxygen between $O(4)$ and $\mathrm{O}(5)$ positions (consistently with the notation of [33]) and formation of the local areas with tetragonal structure.

It can be seen that the qualitative behavior of the temperature dependence of conductivity before and after irradiation remains quasimetallic. Moreover, in the $\rho_{a b}(T)$ dependences in the region of relatively high temperatures, in not irradiated and in irradiated crystals, a rather wide linear region remains, which, according to the NAFL theory [34], is a reliable sign of the normal state of the system. After irradiation, the absolute value of the electrical resistivity increases, and the region of existence of the $\rho_{a b}(T)$ linear dependence decreases substantially at the high temperatures.

As can be seen from the Table, as well as the insert to Fig. 1, after irradiation, the critical temperature is lowered. Herewith, the narrow initial width of the superconducting transition $\left(\Delta T_{c} \leq 0.3 \mathrm{~K}\right)$ increases substantially, which serves as a sign of the

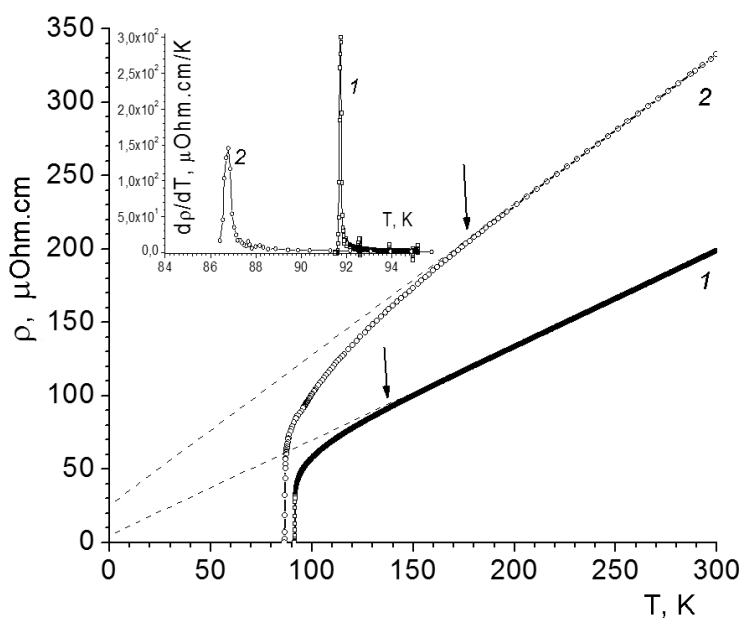

Fig. 1. Plot of $\rho(T)$ dependences obtained before (1) and after (2) electron-irradiation of the crystal. Insert: dependence $d \rho_{a b} / d T-T$ in the superconducting transition region. The numbering of the curves on the inserts corresponds to the numbering in the figure.

appearance of several phases in the sample [14,31], having, respectively, different critical temperatures of the transition to the superconducting state. As the temperature is lowered below a certain characteristic value $T^{*}$, a deviation of $\rho_{a b}(T)$ from the linear dependence occurs, which indicates the appearance of some excess conductivity, which, as noted above, is due to transition to the pseudogap regime [5-7]. The "rounding" of the $\rho_{a b}(T)$ curves below the certain characteristic temperature $T^{*}$ is due to the appearance of excess conductivity, the temperature dependence of which can be obtained from the formula:

$$
\Delta \sigma=\sigma-\sigma_{0}
$$

where $\sigma_{0}=\rho_{0}^{-1}=(A+B T)^{-1}$ is conductivity, determined by interpolating the linear portion of the measurements observed in the high-temperature region to the zero temperature, and $\sigma=\rho^{-1}$ is the experimentally measured value of the conductivity at $T<T^{*}$. 
It is known that near $T_{c}$ the excess conductivity is probably caused by the fluctuational pairing of the current carriers and can be described by the power law dependence obtained in the theoretical LawrenceDoniach model [15], assuming the presence of a very smooth crossover from two-dimensional to three-dimensional fluctuation conductivity regime by decreasing the sample temperature:

$$
\Delta \sigma=\left[\frac{e^{2}}{16 \hbar d}\right] \varepsilon^{-1}\left\{1+J \varepsilon^{-1}\right\}^{-1 / 2},
$$

where $\varepsilon=\left(T-T^{m f}{ }_{c}\right) / T^{m f}{ }_{c}$ is the reduced temperature; $T^{m f}{ }_{c}$ is the critical temperature in the mean-field approximation; $J=\left(2 \xi_{c}(0) / d\right)^{2}$ is the constant of the interplanar pairing; $\xi_{c}$ is the coherence length along $c$ axis and $d$ is the thickness of the two-dimensional layer. In the limiting situations (near $T_{c}$, when $\xi_{c}>d$ - interaction between the fluctuation cooper pairs is realized in the entire volume of the superconductor - $3 \mathrm{D}$ regime or far from $T_{c}$, when $\xi_{c}<<-$ interaction is possible only in the planes of the conducting layers - 2D-regime) expression (2) is transformed into known relations for three- and two-dimensional cases from the AslamazovLarkin theory [9]:

$$
\begin{gathered}
\Delta \sigma_{2 D}=\frac{e^{2}}{16 \hbar d} \varepsilon^{-1}, \\
\Delta \sigma_{3 D}=\frac{e^{2}}{32 \hbar \xi_{c}(0)} \varepsilon^{-1 / 2} .
\end{gathered}
$$

In the case of comparison with the experimental data, it is important to accurately determine the value of $T^{m f}{ }_{c}$, which has significant effect on the slope in the $\Delta \sigma(\varepsilon)$ dependences. Usually, when compared with the experimental data, $\xi_{c}(0), d$ and $T_{c}$ in equations $(2-4)$ are adjustable parameters [1]. However, when using such a technique, as a rule, there are significant quantitative discrepancies between the theory and experiment. This, in turn, makes to use, as an additional fitting parameter, a scaling factor, the so-called $C$-factor, which allowing to combine the experimental data with the calculated ones and, thus, takes into account the possible inhomogeneity of the spreading of the transport current for each particular sample [35]. In our case, $T^{m f}{ }_{c}$ was taken as the $T_{c}$, determined, as noted above, at the maximum point on the $d \rho_{a b} / d T(T)$ curves in the superconducting

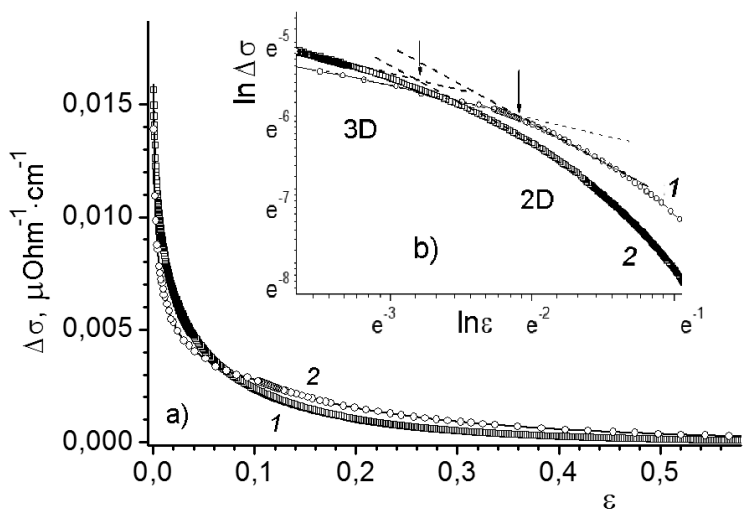

Fig. 2. $\Delta \sigma(T)$ dependences in $\Delta \sigma-\varepsilon$ (a) and $\ln \Delta \sigma-\ln \varepsilon$ (b) coordinates. The numbering of the curves corresponds to the numbering in Fig. 1.

transition region $[11,13]$, as shown in the inset to Fig. 1.

Figure 2 shows $\Delta \sigma(T)$ dependences in $\ln \Delta \sigma(\ln \varepsilon)$ coordinates. It is seen that directly near $T_{c}$ these dependences are satisfactorily approximated by the straight lines with an slope angle $\alpha_{1} \approx-0.5$ corresponding to the exponent $-1 / 2$ in Eq. (4), which indicates the three-dimensional character of the fluctuation superconductivity in this temperature interval. With a further increase in temperature, the rate of decrease $\Delta \sigma$ significantly increases $\left(\alpha_{2} \approx-1\right)$, which, in turn, can be regarded as an indication of the change in the dimension of the phase transition. As follows from Eqns. (3) and (4), at the 2D-3D crossover point:

$$
\varepsilon_{0}=4\left[\xi_{c}(0) / d\right]^{2} \text {. }
$$

In this case, having determined the value $\varepsilon_{0}$ and using the data from the bibliography regarding the dependence of $T_{c}$ and the interplanar distance from $\delta[36,37]$, we can calculate the values of $\xi_{c}(0)$. As it can be seen from the Table, after irradiation, the value $\xi_{c}(0)$ calculated according to Eqn. (5) increases from 1.44 to $2.02 \AA$, which agrees qualitatively with the dependence of $\xi_{c}(0)$ from $\delta$ obtained on the $\mathrm{YBa}_{2} \mathrm{Cu}_{3} \mathrm{O}_{7-\delta}$ samples by decreasing $T_{c}$ [31], but it is significantly smaller from the absolute value of $\xi_{c}(0)$ from the values obtained in [31] with a similar decrease in $T_{c}$ as a result of decrease in the oxygen content.

As noted above, the electron irradiation is accompanied by significant expansion of the region of existence of excess conductivity toward the high temperatures $T>1.5 T_{c}$, 
which obviously cannot be explained within the framework of the existing fluctuation theories. According to contemporary concepts (see, for example, [5-7]), such a behavior of the $\rho_{a b}(T)$ dependences can be caused by the transition to the so-called pseudogap state, characteristic for the "underdoped" compositions of the HTSC compounds.

The reduced dependences $\Delta \sigma(T)$ are presented in Fig. 3 in $\ln \Delta \sigma$ versus $1 / T$ representation. In a rather broad temperature range these dependences fit to the straight lines described by the following exponential dependence:

$$
\Delta \sigma \sim \exp \left(\Delta^{*}{ }_{a b} / T\right),
$$

and assuming some thermally activated process over the pseudogap $\Delta^{*}{ }_{a b}$. The values of $\Delta^{*}$ before and after irradiation are reported in Table. The electron irradiation has led to a reduction of the absolute value of the pseudogap $\Delta^{*}{ }_{\mathrm{K} 1} / \Delta^{*}{ }_{\mathrm{K} 2}$ by a factor of about 1.45 .

The exponential temperature dependence of $\Delta \sigma(T)$ was earlier observed for as-grown samples of YBaCuO [3, 27]. As it was revealed, the approximation of experimental data can be substantially extended by introduction of the factor $\left(1-T / T^{*}\right)$ in Eq. (6). In this case the excess conductivity turns out proportional to the density of the superconducting charge carriers $n_{s} \sim\left(1-T / T^{*}\right)$ and inversely proportional to the number of pairs $\sim \exp \left(-\Delta^{*} / k T\right)$ broken by thermal motion:

$$
\Delta \sigma \sim\left(1-T / T^{*}\right) \exp \left(\Delta^{*}{ }_{a b} / T\right) .
$$

In Eq. (7), $T^{*}$ is considered as the meanfield superconducting transition temperature. The temperature range $T_{c}<T<T^{*}$ of the pseudogap state is determined by the phase stiffness of the order parameter that depends on the oxygen content and the defect concentration. In this way, employing the approach proposed in [3,27], the experimental data $\ln \Delta \sigma$ allow one to plot the temperature dependence $\Delta^{*}{ }_{a b}(T)$ up to $T^{*}$. The pseudogap temperature dependences deduced by this approach are shown by curves 1 and 2 in insert in Fig. 3 in $\Delta^{*}(T) / \Delta_{\max }$ versus $T / T^{*}$ representation, where $\Delta_{\max }$ is the value of $\Delta^{*}$ on the plateau far from $T^{*}$.

In the theoretical work [38] the pseudogap temperature dependences were derived in the mean-field approximation within the framework of the BSC-BEC

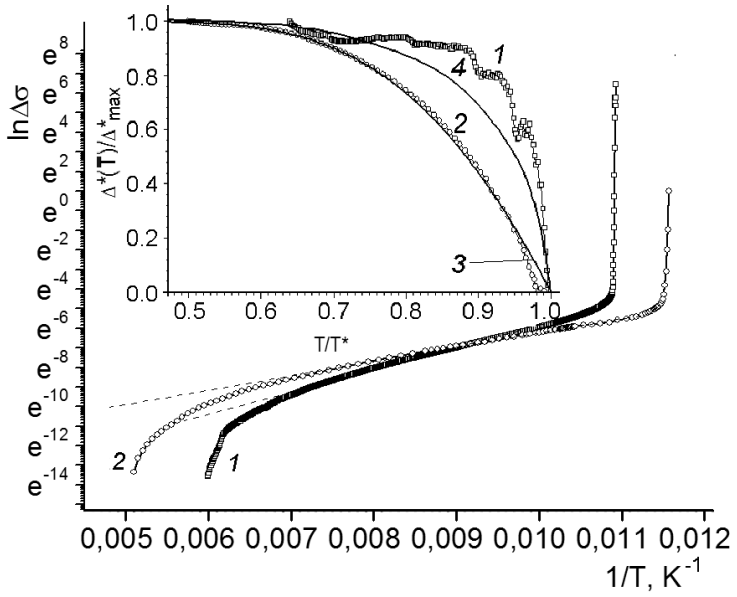

Fig. 3. Temperature dependences of the excess conductivity of $\mathrm{YBa}_{2} \mathrm{Cu}_{3} \mathrm{O}_{7-\delta}$ single crystal before (1) and after (2) electron irradiation in $\ln (\Delta \sigma)$ versus $1 / T$ representation. Dashed lines are fits to Eq. (6). Inset: temperature dependences of the pseudogap in $\Delta^{*}(T) / \Delta^{*}$ max versus $T / T^{*}$ representation. $\Delta^{*}{ }_{\text {max }}$ is the value of $\Delta^{*}$ on the plateaus far from $T^{*}$. The curve numbering corresponds to Fig. The dependences $\Delta^{*}(T) / \Delta(0)$ versus $T^{\prime} / T^{*}$ calculated by Eqs. (8) and (9) [38] are shown by solid lines (3) and (4), respectively.

crossover theory for the cases of weak [Eq. (8)] and strong [Eq. (9)] coupling:

$$
\begin{gathered}
\Delta(T)=\Delta(0)-\Delta(0) \sqrt{2 \pi \Delta(0) T} \exp \left[-\frac{\Delta(0)}{T} \text { righ }(\beta,)\right. \\
\Delta(T)= \\
=\Delta(0)-\frac{8}{\sqrt{\pi}} \sqrt{-x_{0}}\left(\frac{\Delta(0)}{T}\right)^{3 / 2} \exp \left[-\frac{\sqrt{\mu^{2}+\Delta^{2}(0)}}{T}\right]
\end{gathered}
$$

where $x_{0}=\mu / \Delta(0)$ with $\mu$ being the chemical potential of the system of charge carriers and $\Delta(0)$ is the superconducting gap at $T=0$.

The dependences $\Delta^{*}(T) / \Delta(0)$ on $T / T^{*}$ calculated by Eqs. (8) and (9) for the crossover parameter $\mu / \Delta(0)=10$ (BCS limit) and $\mu / \Delta(0)=-10$ (BEC limit) are shown in insert in Fig. 3 by dash lines (3) and (4), respectively. One sees that the pseudogap temperature dependence of the optimally doped, impurity-free as-grown sample noticeably deviates from the theoretical curve [38], as this was the case for the YBCO thin films with the same oxygen content [27]. At the same time, for the irradiated sample, even admitting the conditionality in the determination of the pseudogap opening temperature $T^{*}$ from the downturn of $\rho(T)$ curve 
from the linear law, the experimental data fit to the theoretical curve satisfactory.

From the inset in Fig. 3 it follows that the rapid increase of $\Delta \sigma$ ensues when $T$ approaches TC. From the theory $[9,15]$ it is known that near $T_{c}$ the excess conductivity is stipulated by the fluctuational pairing of the charge carriers. If the temperature $T_{f}$ corresponding to the transition from the pseudogap state to the regime of fluctuation conductivity is determined at the point where $\ln \Delta \sigma$ starts to turn up from the linear law $\ln \Delta \sigma(1 / T)$ [27], then one can estimate the temperature range where the pseudogap state exists as $t^{*}=\left(T^{*}-T_{f}\right) / T_{f}$. The calculations reveal that electron irradiation causes a relative expansion of the pseudogap temperature range by more than $50 \%$, from $t^{*}=0.3029$ to $t^{*}=0.4869$. A certain role at this can be played by other specific mechanisms of quasiparticle scattering [39-43] stipulated by the structural and kinematic anisotropy in the system.

\section{Conclusions}

The results of this work can be summarized as follows. The excess conductivity $\Delta \sigma(T)$ of optimally doped $\mathrm{YBa}_{2} \mathrm{Cu}_{3} \mathrm{O}_{7-\delta}$ single crystals both, before and after electron irradiation obeys the exponential temperature dependence in a broad range of temperatures $T_{f}<T<T^{*}$. The description of the excess conductivity by the relation $\Delta \sigma \sim(1-$ $\left.T / T^{*}\right) \exp \left(\Delta^{*}{ }_{a b} / T\right)$ can be interpreted in terms of the mean-field theory where $T^{*}$ is the mean-field transition temperature to the pseudogap state and $\Delta \sigma(T)$ is satisfactory described within the framework of the BCS$\mathrm{BEC}$ crossover theory. In all, electron irradiation of the $\mathrm{YBa}_{2} \mathrm{Cu}_{3} \mathrm{O}_{7-\delta}$ single crystals has been revealed to lead to an expansion of the temperature range where the pseudogap state exists, thereby narrowing the range of the linear dependence of $\rho(T)$ in $a b$-plane, while the coherence length increases by almost one and a half times and the crossover point shifts substantially with temperature.

\section{References}

1. T.A.Friedmann, J.P.Rice, J.Giapintzakis, D.M.Ginsberg, Phys. Rev. B, 39, 4258 (1989).

2. R.V.Vovk, G.Ya.Khadzhai, I.L.Goulatis, A.Chroneos, Physica B, 436, 88 (2014).

3. R.V.Vovk, N.R.Vovk, G.Ya.Khadzhai et al., Current Appl. Phys., 14, 1779 (2014).

4. A.V.Bondarenko, A.A.Prodan, M.A.Obolenskii et al., Low Temp. Phys., 27, 339 (2001).
5. M.V.Sadovskii, I.A.Nekrasov, E.Z.Kuchinskii et al., Phys. Rev. B, 72, 155105 (2005).

6. R.V.Vovk, N.R.Vovk, G.Ya.Khadzhai, O.V.Dobrovolskiy, Solid State Communication, 204, 64 (2015).

7. A.L.Solovyov, L.V.Omelchenko, V.B.Stepanov et al., Phys. Rev. B, 94, 224505 (2016).

8. N.A.Azarenkov, V.N. Voevodin, R.V.Vovk et al., J. Mater.Sci.:Mater. Electr., 28, 15886 (2017).

9. L.G.Aslamazov, A.I.Larkin, Phys.Lett., 26A, 238 (1968).

10. A.L.Solovjov, L.V.Omelchenko, R.V.Vovk et al., Physica B, 493, 58 (2016).

11. H.A.Borges, M.A.Continentino, Solid State Commun. 80, 197 (1991).

12. R.V.Vovk, M.A.Obolenskii, A.A.Zavgorodniy et al., J.Mater.Sci: Mater. in Electron., 18, 811 (2007).

13. L.M.Ferreira, P.Pureur, H.A.Borges, P.Lejay, Phys.Rev. B, 69, 212505 (2004).

14. R.V.Vovk, G.Ya.Khadzhai, O.V.Dobrovolskiy et al., Mod.Phys. Lett. B, 30, 1650188 (2016).

15. W.E.Lawrence, S.Doniach, in: Proc. of the 12 th Intern. Conf. on Low Temperature Physics, Kyoto, Japan, 1970, ed. by E.Kanda (Keigaku, Tokyo, 1970), p.361.

16. J.B.Bieri, K.Maki, R.S.Thompson, Phys.Rev. $B, 44,4709$ (1991).

17. A.L.Solovjov, M.A.Tkachenko, R.V.Vovk, A.Chroneos, Physica C, 501, 24 (2014). http:dx.doi.org10.1016j.physc.2014.03.004.

18. R.V.Vovk, N.R.Vovk, G.Ya.Khadzhai et al., Physica B, 422, $33 \quad$ (2013). http:dx.doi.org10.1016j.physb.2013.04.032.

19. R.V.Vovk, Y.I.Boiko, V.V.Bogdanov et al., Physica C, 536, 26 (2013).

20. R.V.Vovk, N.R.Vovk, G.Ya.Khadzhai et al., J. Mater. Sci: Mater. Electron., 25, 5226 (2014). doi 10.1007s10854-014-2292-5.

21. W.K.Kwok, S.Fleshler, U.Welp et al., Phys. Rev. Lett. 69, 3370 (1992).

22. R.V.Vovk, Z.F.Nazyrov, M.A.Obolenskii et al., J.Alloys Compds., 509, 4553 (2011).

23. A.V.Bondarenko, V.A.Shklovskij, R.V.Vovk et al., Low Temp. Phys., 23, 962 (1997).

24. Yu.T.Petrusenko, I.M.Neklyudov, A.N.Sleptsov et al., Physica B, 169, 711 (1991).

25. M.K.Wu, J.R.Ashburn, C.J.Torng et al., Phys. Rev. Lett., 58, 908 (1987).

26. H.Lutgemeier, S.Schmenn, P.Meuffels et al., Physica C, 267, 191 (1996).

27. R.V.Vovk, M.A.Obolenskiy, A.A.Zavgorodniy et al., Physica B, 404, 3516 (2009).

28. Physical Properties High Temperature Superconductors, ed. by D.M.Ginsberg, I.-Singapore: Word Scientific (1989).

29. R.V.Vovk, N.R.Vovk, O.V.Dobrovolskiy et al., J. Low Temp.Phys., $1, \quad 17$ (2014). doi 10.1007s10909-014-1121-9.

30. A.V.Bondarenko, A.A.Prodan, Yu.T.Petrusenko et al., Phys. Rev., 64, 092513 (2001) . 
31. M.A.Obolenskii, R.V.Vovk, A.V.Bondarenko, N.N.Chebotaev, J.Low Temp. Phys., 32, 571 (2006).

32. J.M.Valles, Jr., A.E.White, K.T.Short et al., Phys. Rev. B, 39, 11599 (1989).

33. T.Siegrist, S.Sunshince, D.W.Murphy et al., PRB, 35, 7137 (1987).

34. B.P.Stojkovic, D.Pines, Phys. Rev.B, 55, 8567 (1997).

35. A.L.Solov'ev, H.U.Habermeier, T.Haage, $J$. Low Temp. Phys., 28, 144 (2002).

36. G.D.Chryssikos, E.I.Kamitsos, J.A.Kapoutsis et al., Physica C, 254, 62 (1995).

37. R.V.Vovk, M.A.Obolenskii, Z.F.Nazyrov et al., J.Mater.Sci.:Mater.Electr., $\quad 23, \quad 1255$ (2012). doi 10.1007s10854-011-0582-8.
38. E.Babaev, H.Kleinert, Phys.Rev. B, 59, 12083 (1999).

39. R.V.Vovk, C.D.H.Williams, A.F.G.Wyatt, Phys.Rev. B, 68, 134508 (2003)

40. R.V.Vovk, C.D.H.Williams, A.F.G.Wyatt. Phys.Rev.Lett., 91, 235302 (2003).

41. D.H.S.Smith, R.V.Vovk, C.D.H.Williams, A.F.G.Wyatt, Phys.Rev.B, 72, 054506 (2005).

42. R.V.Vovk, C.D.H.Williams, A.F.G.Wyatt, Phys. Rev. B, 69, 144524 (2004).

43. A.L.Solovjov, L.V.Omelchenko, R.V.Vovk et al., Current Appl.Phys., 16, 931 (2016). 